\title{
PENGEMBANGAN GAME 3D “EVERPLANE" DENGAN LEAP MOTION
}

\author{
${ }^{1}$ Galang Ihsan Isnanto, ${ }^{2}$ Samuel Gandang Gunanto, ${ }^{3}$ Agnes Karina Pritha Atmani \\ ${ }^{1}$ Program Studi Animasi, Fakultas Seni Media Rekam, Institut Seni Indonesia Yogyakarta \\ asligalang@gmail.com, \\ ${ }^{2}$ Program Studi Animasi, Fakultas Seni Media Rekam, Institut Seni Indonesia Yogyakarta \\ gandang@isi.ac.id \\ ${ }^{3}$ Program Studi Animasi, Fakultas Seni Media Rekam, Institut Seni Indonesia Yogyakarta \\ agneskarina@gmail.com
}

\begin{abstract}
Abstrak
Leap Motion (Hand Motion tracking) merupakan istilah untuk perekaman gerakan tangan yang digunakan menjadi model digital dan merupakan perangkat tambahan yang dapat dihubungkan ke komputer dan kemudian dapat digunakan untuk menggantikan fungsi mouse maupun keyboard. Dalam game 3D "Everplane", Leap Motion digunakan sebagai game controller dan merupakan komponen utama dari game. Game Everplane merupakan game berjenis endless game / endless runner. Endless runner adalah permainan di mana karakter pemain terus bergerak maju melalui dunia game yang tanpa akhir. Game Everplane memiliki konsep menjelajah luar angkasa. Proses pembuatan game 3D "Everplane" melalui berbagai riset data yang diperlukan guna memenuhi kebutuhan produksi game yang melalui 3 tahapan yaitu Praproduksi (Game Design, Desain Karakter dan Layout Design), Produksi (Modelling, Texturing, Design graphic user interface, Music, Setup Leap Motion, Assembly Animating, Programming, dan Problem solfing) dan Pascaproduksi (Deploying, Mastering dan Merchandise).
\end{abstract}

Kata kunci : Leap Motion, game Everplane, proses pembuatan

\begin{abstract}
Motion Leap (Hand Motion tracking) is a term for recording hand movements used as digital models and is an additional device that can be connected to a computer and can then be used to replace both mouse and keyboard functions. In the 3D game "Everplane", Leap Motion is used as a game controller and is the main component of the game. The Everplane game is an endless game / endless runner type game. Endless runner is a game where the player's character continues to move forward through the endless world of games. The Everplane game has the concept of exploring space. The process of making $3 D$ games "Everplane" through various data research is needed to meet the needs of game production through three stages, namely Preproduction (Game Design, Character Design and Layout Design), Production (Modeling, Texturing, Design graphic user interface, Music, Leap Setup Motion, Assembly Animating, Programming, and Problem Solfing) and Postproduction (Deploying, Mastering and Merchandise).
\end{abstract}

Keywords: Leap Motion, Everplane game, manufacturing process 


\section{PENDAHULUAN}

Game Everplane merupakan game berjenis endless game / endless runner. Endless runner adalah permainan di mana karakter pemain terus bergerak maju melalui dunia game yang tanpa akhir. Game Everplane memiliki konsep menjelajah luar angkasa. Kontrol game terbatas untuk menghindari meteor. Tujuan permainan ini adalah untuk berjalan sejauh mungkin sebelum karakter mati.

Pemilihan gameplay bermodel endless runner dikarenakan endless runner ini merupakan model permainan yang dirasa cocok dengan karakter pesawat terbang dan untuk meminimalisir permodelan aset game karena model gameplay endless runner hanya membutuhkan 1 scene asset game. Game Everplane memakai algoritma collision detection. Collision detection adalah proses mendeteksian tabrakan antara dua objek. Tabrakan yang dimaksud adalah tabrakan antara obyek meteor dan obyek pesawat yang dikendalikan dengan Leap Motion.

Leap Motion merupakan perangkat tambahan yang dapat dihubungkan ke komputer dan kemudian dapat digunakan untuk menggantikan fungsi mouse dan keyboard. Fungsi dari alat yang bernama Leap Motion ini, dapat membantu penggunanya mengendalikan atau menggantikan tugas game controller hanya dengan gerakan tangan dan jari.

Bentuk Leap Motion ini berukuran kotak yang cukup kecil sehingga mudah dibawa kemanapun. Cara kerja Leap Motion ini adalah pengguna menghubungkan perangkat ke komputer, kemudian Leap Motion akan mendeteksi keberadaan tangan maupun jari yang selanjutnya pengguna dapat menggunakan gerakan tangan atau jari yang diinginkan serta gerakan kombinasi yang sudah diatur.

Interpretasi visual dari gerakan tangan secara alami telah menjadi bagian penting untuk berinteraksi dengan mesin dalam kehidupan sehari-hari. Seperti contohnya populernya penggunaan mouse dan keyboard sebagai alat bantu dalam mencapai kemudahan dalam berinteraksi dengan komputer, namun pada tugas akhir ini, leap motion digunakan sebagai game controller untuk game Everplane. 


\section{RUMUSAN MASALAH}

Berdasarkan latar belakang dapat dirumuskan permasalahan yang akan diselesaikan sebagai berikut:

1. Bagaimana memproduksi game 3D berjenis endless game.

2. Bagaimana menerapkan sensor leap motion sebagai game controller.

3. Belum banyaknya game developer yang melirik leap motion sebagai game controller.

\section{TUJUAN}

Tujuan dari penciptaan game 3D Everplane antara lain:

1. Memproduksi game 3D dengan jenis endless game.

2. Memproduksi game 3D dengan memanfaat leap motion sebagai game controller.

3. Mengeksploitasi kegunaan dari Leap Motion selain untuk menggantikan mouse dan keyboard.

\section{TARGET AUDIEN}

Target audien dari game 3D Everplane ini adalah:
1. Usia
: 7 + IGRS (IGRS.id, 2016)
2. Jenis kelamin
: Laki-laki dan perempuan
3. Pendidikan
: Berbagai latar pendidikan
4. Status sosial
: Semua kalangan
5. Negara
: Internasional
6. Perangkat
: Windows PC

\section{INDIKATOR CAPAIAN AKHIR}

Capaian akhir dari game ini adalah benar-benar menjadi satu game 3D utuh, dengan tahapan sebagai berikut:

\section{Game Design}

Game Design, bagian dari pengembangan permainan, adalah proses mendesain atau merancang konten dan peraturan permainan dalam tahap pra-pembuatan dan perancangan tata permainan, lingkungan, alur cerita, dan karakter selama tahap 
pembuatan (Adams, 2010, hal. 3). Istilah ini juga digunakan untuk menjelaskan desain permainan yang ada di dalam suatu permainan dan dokumentasi yang menjelaskan desain seperti itu. Desain permainan memerlukan keahlian artistik dan teknis serta kemampuan menulis yang baik dan benar.

\section{Modelling}

Modelling yang dimaksud adalah proses untuk menciptakan objek 3D yang ingin dituangkan dalam bentuk visual nyata, baik secara bentuk, texture, dan ukuran objeknya. Pengertian lainnya adalah sebuah teknik dalam komputer grafis untuk memproduksi representasi digital dari suatu objek dalam tiga dimensi (baik benda mati maupun hidup).

\section{Graphic User Interface Design}

Graphic user interface memiliki pengertian sebagai sebuah bentuk tampilan yang berhubungan langsung dengan pengguna dan graphic user interface berfungsi untuk menghubungkan antara pengguna dengan sistem operasi sehingga komputer dapat dioperasikan. Maka dapat disimpulkan bahwa graphic user interface merupakan serangkaian tampilan grafis yang dapat dimengerti oleh pengguna komputer dan diprogram sedemikian rupa sehingga dapat terbaca oleh sistem operasi komputer dan beroperasi sebagaimana mestinya.

\section{Programming}

Programming adalah proses menulis, menguji dan memperbaiki (debug), dan memelihara kode yang membangun suatu program komputer. Kode ini ditulis dalam berbagai bahasa pemrograman. Tujuan dari programming adalah untuk membuat suatu program yang dapat melakukan suatu perhitungan atau 'pekerjaan' sesuai dengan keinginan si pemrogram. Untuk melakukan programming, diperlukan keterampilan dalam algoritma, logika, bahasa pemrograman, dan pada banyak kasus, pengetahuanpengetahuan lain seperti matematika.

\section{Debugging}

Debugging adalah sebuah metode yang dilakukan oleh para programmer dan pengembang perangkat lunak untuk mencari dan mengurangi bug, atau kerusakan di 
dalam sebuah program komputer sehingga program tersebut dapat bekerja sesuai dengan harapan. Debuging dilakukan bersamaan dengan proses programming .

\section{Music Scoring}

Music scoring merupakan proses pembuatan musik yang akan disematkan pada game Everplane. Proses music scoring dilakukan dengan software flStudio.

\section{Mastering}

Tahap final dalam proses pembuatan game Everplane yaitu burning ke dalam DVD-R dan di-upload ke Google Drive guna keperluan dokumentasi.

\section{PEMBAHASAN}

Leap Motion (Hand Motion tracking) merupakan istilah untuk perekaman gerakan tangan yang digunakan menjadi model digital dan merupakan perangkat tambahan yang dapat dihubungkan ke komputer dan kemudian dapat digunakan untuk menggantikan fungsi mouse maupun keyboard. Fungsi dari alat yang bernama Leap Motion ini, dapat membantu penggunanya mengendalikan atau menggantikan tugas mouse maupun keyboard pada komputer hanya dengan gerakan tangan dan jari.

Bentuk Leap Motion ini berukuran kotak yang cukup kecil sehingga mudah dibawa kemanapun. Cara kerja Leap Motion ini adalah pengguna menghubungkan perangkat ke komputer, lalu cukup meletakkannya di depan monitor atau di dekat komputer yang pasti jangan sampai diluar jangkauan kabelnya. Kemudian Leap Motion akan mendeteksi keberadaan tangan maupun jari yang selanjutnya pengguna dapat menggunakan gerakan tangan atau jari yang diinginkan serta gerakan kombinasi yang sudah diatur.

Perkembangan Leap Motion yang diaplikasikan ke dalam game 3D Everplane memalui proses riset dan data untuk memastikan bahwa Leap Motion sanggup untuk diaplikasikan ke dalam software Unity. Proses ini mengalami kendala dikarenakan minimnya informasi yang tersedia di media online. Minimnya informasi ini disebabkan oleh pengguna sensor Leap Motion yang sudah berkurang pada saat ini.

Pembuatan game 3D Everplane ini melalui beberapa proses seperti riset data sensor Leap Motion dan riset data pesawat, modelling asset game dengan menggunakan low poly teknik, texturing asset game dengan software substance Painter, assembling 
pada software Unity, music scoring di software FLStudio, dan programming game pada Unity game engine.

Proses produksi berjalan dengan mendapat berbagai masukan dari game tester, dosen pembimbing dan dosen game. Berbagai improvisasi seperti penggantian pesawat imajiner dengan pesawat yang sesungguhnya merupakan perubahan yang paling banyak. Perubahan ini dilakukan guna memberikan informasi tentang sejarah berbagai macam pesawat yang pernah dipakai negara Indonesia untuk mencapai kemerdekaan. Hal ini mengakibatkan perubahan layout dimana layout yang sebelumnya tampak sepi, kini menjadi ramai akan informasi dari masing masing pesawat.

\section{Leap Motion Controller}

Banyaknya game yang berkembang sekarang ini diikuti dengan munculnya berbagai controller game seperti gamepad, paddle, joystick, track ball, light gun, dan baru - baru ini munculah Leap Motion. Leap Motion adalah sebuah alat yang digunakan untuk mendeteksi gerakan tangan dan jari manusia di udara lalu menjadikannya sebagai input agar bisa diproses oleh program komputer.

Leap Motion ini dikembangkan oleh David Holz dan Michael Buckwald (Richardson, 2013). Mereka mengembangkan perangkat mirip Microsoft Kinect namun diklaim memiliki tingkat akurasi yang lebih tinggi. Cara kerja Leap Motion adalah dengan menciptakan ruang 4 kaki kubik interaktif yang mampu mendeteksi jari, tangan dan gerakan lengan.

Teknologi Leap Motion memang serupa dengan Kinect, namun Leap Motion ini jauh lebih canggih dan akurat. Hal ini karena perbedaan metode kerja yang digunakan Kinect dengan Leap Motion. David Holz dan Michael Buckwald mengatakan bahwa Leap Motion adalah suatu lompatan teknologi yang menguntungkan bagi sistem komputer dan sistem operasi. Apa yang bisa dilakukan oleh mouse, Leap Motion dapat lakukan. Di kantor pusat Leap Motion, terdapat beberapa demo teknologi Leap Motion berupa Game Fruit Ninja yang dimainkan menggunakan Leap Motion. 


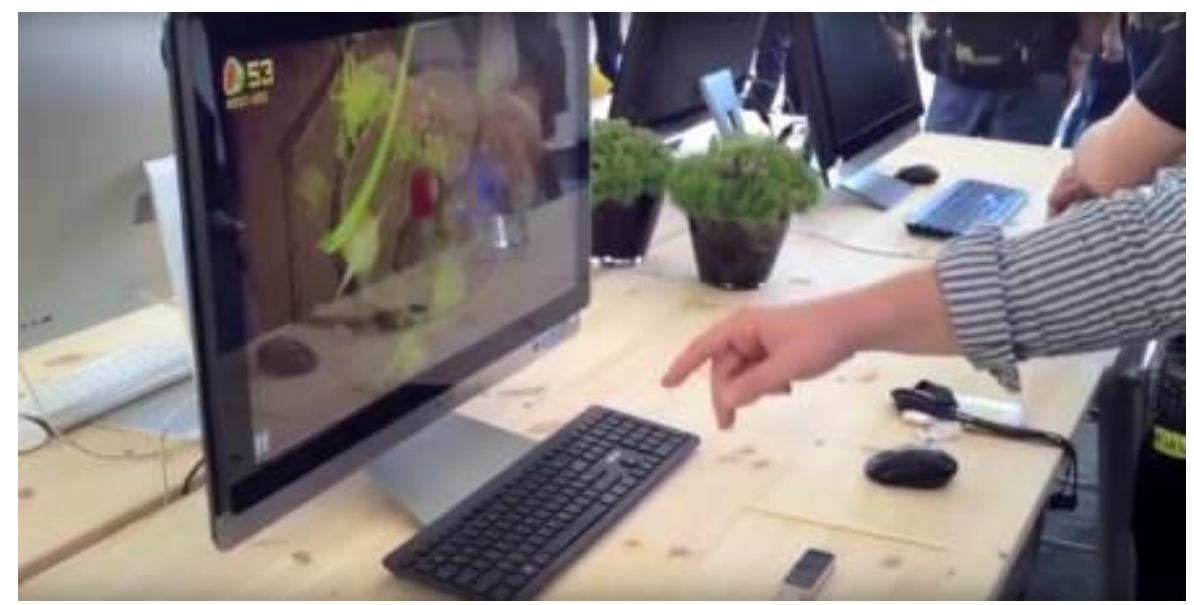

Gambar 1. Permainan Fruit Ninja dengan sensor Leap Motion

Leap Motion mendeteksi gerakan tangan manusia menggunakan dua inframerah monokrom dan tiga inframerah jenis led yang mampu mendeteksi area setengah lingkaran dengan dimensi 3D tepat di atas alat ini. Pada awal perkembangannya, alat ini hanya digunakan sebagai pengganti mouse untuk mengontrol komputer seperti membuka folder, scroll up, scroll down, dan fungsi dasar computer lainnya, namun dalam game Everplane ini Leap Motion digunakan sebagai pengendali pesawat di dalam gameplay.

\section{Start Screen}

Tampilan start screen memiliki bentuk unik yang terfokus pada bendera yang berkibar dan tulisan Everplane pada tengah layar. Main menu dibuat berdasar referensi dari game Apex Legend yang juga menggunakan bendera berkibar pada background game. Terdapat ilustrasi interaksi tangan yang mengikuti gerakan tangan pemain. Asap dan percikan api ditambahkan guna memberi kesan dramatis pada game.

Pojok kiri bawah dari scene ini diisi petunjuk untuk menggunakan tangan ke atas jika ingin memulai game. Pada pojok kanan bawah terdapat kalimat terima kasih kepada perorangan ataupun organisasi yang turut andil dalam terciptanya game ini. 


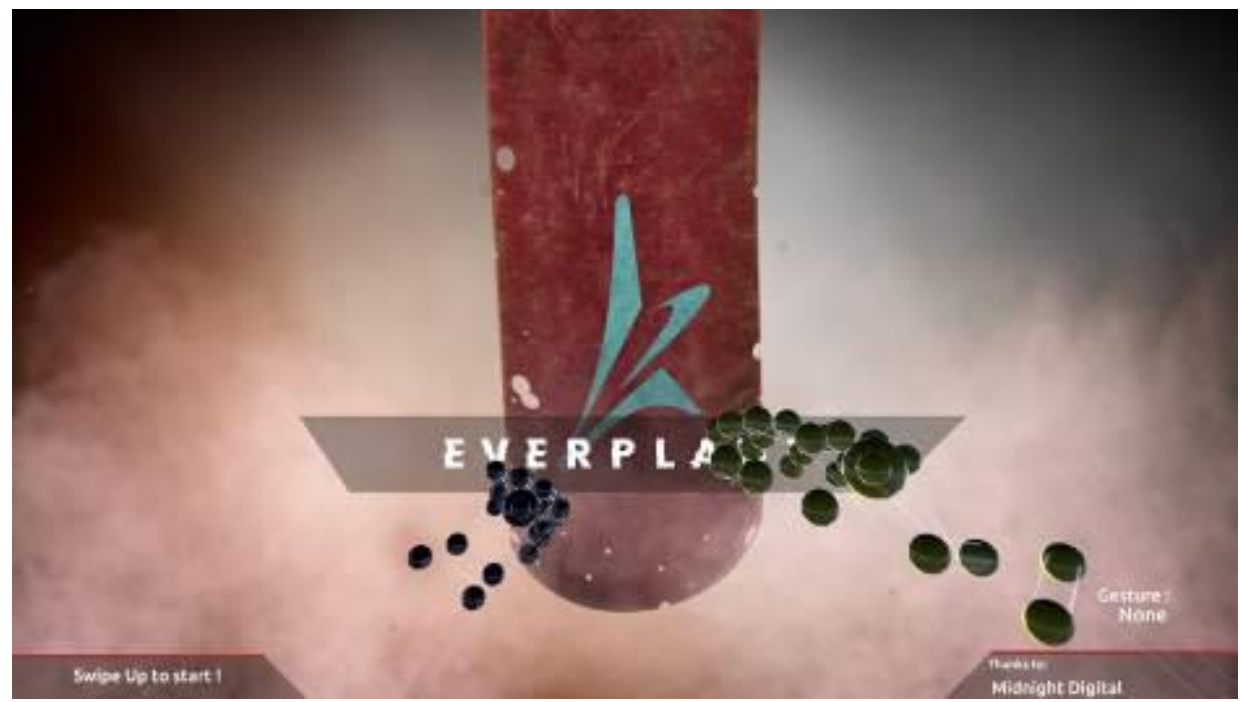

Gambar 2. Tampilan scene start screen

\section{Pilih Pesawat}

Pembuatan scene pilih pesawat mengacu pada scene start screen yang memiliki tema bendera berwarna merah. Asap dan percikan bara api juga ditambahkan guna memberi kesan dramatis pada game.

Scene ini memiliki lebih banyak komponen yang terlihat. Pada bagian pojok kiri atas terdapat nama dari game yakni Everplane beserta logonya. Pada bagian bawah nama dan logo terdapat berbagai informasi tentang pesawat yang sedang aktif. Pada bagian kanan bawah masih sama, yakni kalimat terima kasih kepada perorangan ataupun organisasi yang turut andil dalam terciptanya game ini. Sedangkan di pojok kanan atas terdapat current highscore untuk memotivasi pemain untuk melampauinya.

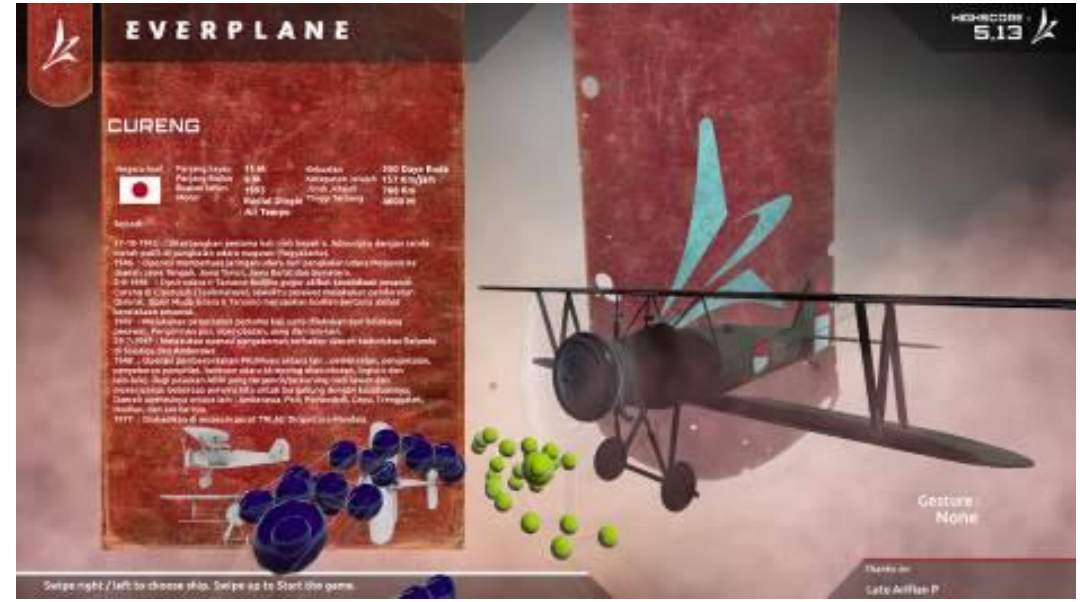

Gambar 3. Tampilan scene pilih pesawat 


\section{Gameplay}

Pemain dapat mengendalikan pesawat dengan cara menggerakkan tangan di atas sensor Leap Motion, secara otomatis pesawat akan mengikuti gerakan tangan. Tugas pemain adalah menghindari meteor yang berterbangan selama mungkin. Di atas layar terdapat tampilan skor yang didapat oleh pemain.

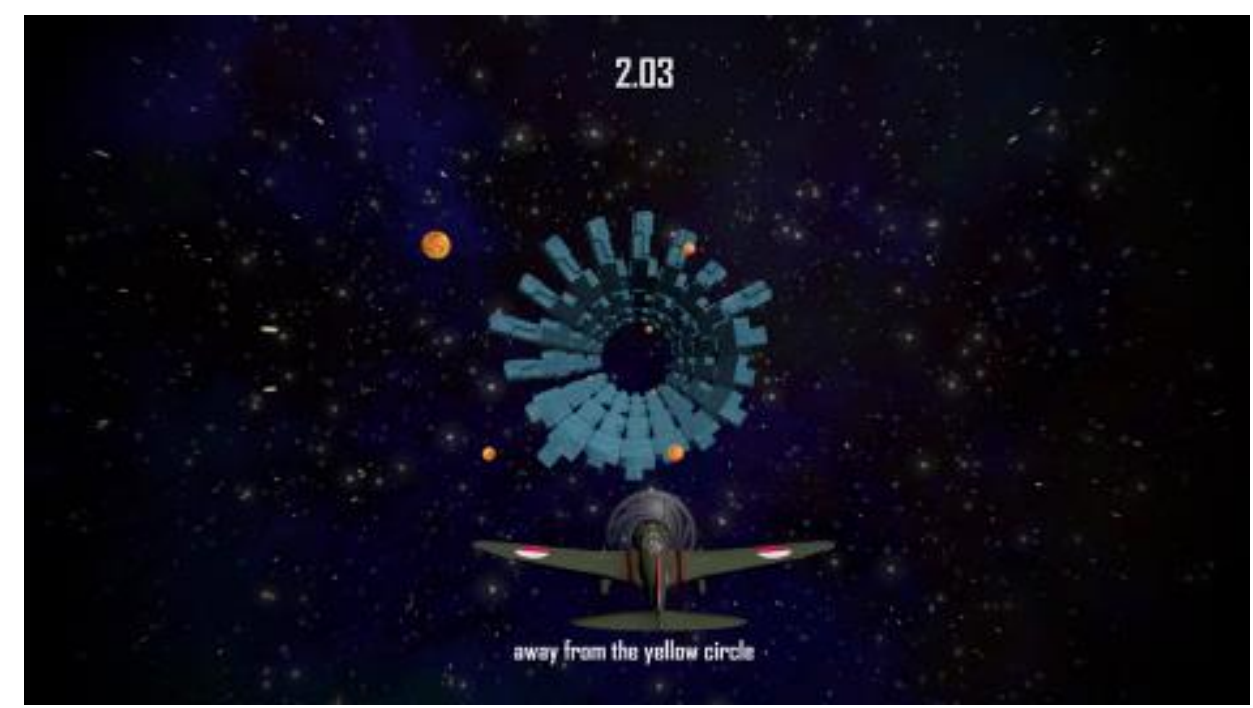

Gambar 4. Tampilan scene gameplay

\section{Game Over}

Scene ini menampilkan hasil score permainan kepada pemain yang dilakukan oleh pemain. Terdapat skor yang didapat, dan terdapat highscore untuk menjadi perbandingan antara skor pemain satu dengan yang lain.

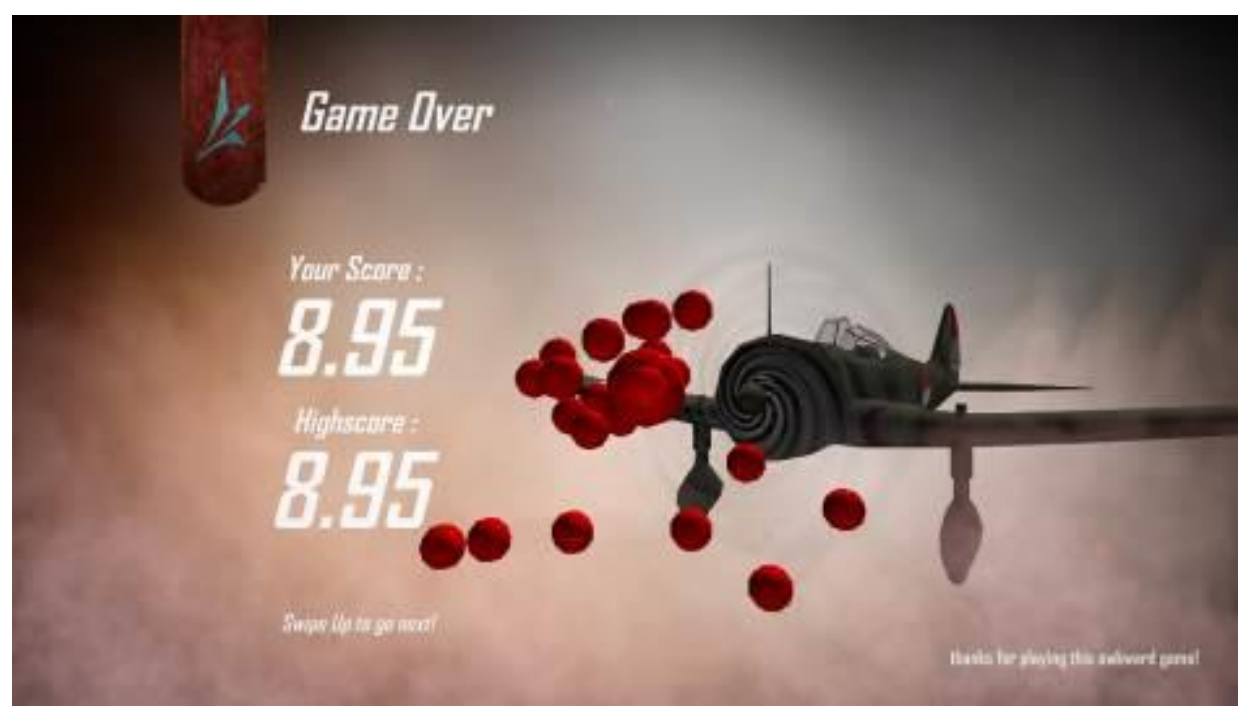

Gambar 5. Tampilan scene game over 


\section{RISET \& DATA}

Riset dan data dilakukan dengan mencari berbagai tutorial di laman internet tentang Leap Motion Development proses. Untuk pembuatan konsep visual memakai metode riset dan data gambar dari berbagai referensi game space shooter yang ditransformasikan menjadi konsep visual original. Sedangkan pengumpulan data pesawat, dilakukan dengan mengunjungi Museum Pusat TNI AU Dirgantara Mandala langsung.

\section{KESIMPULAN}

Kesimpulan yang didapatkan dari seluruh proses pembuatan karya tugas akhir game 3D Everplane:

1. Penciptaan game 3D Everplane selesai dibuat dengan jenis endless game.

2. Penciptaan game 3D Everplane selesai dibuat dengan mengintegrasikan sensor Leap Motion ke dalam game.

3. Penciptaan game 3D Everplane telah selesai dengan sedikit improvisasi seperti penggantian pesawat imajiner dengan pesawat yang sesungguhnya.

4. Game 3D Everplane telah di uji coba untuk OS windows 10 dan dapat dijalankan dengan maksimal.

\section{SARAN}

Seluruh tahapan praproduksi, produksi dan pascaproduksi telah selesai. Adapun beberapa saran yang didapat dari penciptaan game 3D "Everplane" ini antara lain yaitu:

1. Berikan lebih banyak waktu pada tahapan riset data sehingga pada tahap produksi tidak mengalami banyak perubahan atau revisi.

2. Sebaiknya lisensi software harus diperhatikan agar tidak melanggar hukum yang berlaku.

3. Kekurangan pada penguasaan dalam bidang tertentu dapat diatasi dengan cara meminta support, dukungan, atau bantuan dari rekan atau teman.

4. Game ini tersedia untuk sistem operasi Windows. Diharapkan game ini dapat menjadi referensi bagi desainer game lain untuk menciptakan karya yang berbeda dari yang lain dan dapat mengembangkan game ciptaanya tersebut lebih jauh. 


\section{DAFTAR PUSTAKA}

Adams, E. (2010). Fundamentals of game design (Vol. 47). Berkeley: New Riders. https://doi.org/10.5860/choice.47-4462

IGRS.id. (2016). Klasifikasi Permainan Interaktif Elektronik. Diambil 1 Mei 2019, dari https://igrs.id/tentang

Richardson, N. M. (2013, Mei 28). One Giant Leap for Mankind. Inc.com. Diambil dari https://www.inc.com/30under30/nicole-marie-richardson/leap-motion-david-holzmichael-buckwald-2013.html 
Galang Ihsan Isnanto

Pengembangan Game 3D "Everplane" dengan Leap Motion

(HALAMAN INI SENGAJA DIKOSONGKAN) 